\title{
BEN HUR, EL ISRAELITA CONTRA \\ MESALA, EL ROMANO
}

\author{
Jesús López Toledo
}

El tiempo transcurría entre la casa, la escuela y el río. La Escuela Primaria Estatal, "la Morelos", la Federal "la Laureles" y una para niñas, "la Justo Sierra". En un pueblo tan pequeño también había un colegio religioso con internado en el que estudiaban los ricos. Como ocurre siempre, había pleitos entre una escuela y otra, los de la Morelos decían a los de la Laureles, laureleños patas de leño, al mismo tiempo que gritaban rie, cañón y escopeta, a la Morelos se le respeta.

Todavía recuerdo aquellas planas de óvalos, de líneas verticales hacia arriba y hacia abajo, del patito para aprender a escribir el dos. Jamás he olvidado los dibujos del anciano sordo con la mano sobre el oído preguntando $¿ E h$ ? La rata chillando, el jinete gritando ooohh, o el tren pitando su largo uuuuuhhhh. Era el viejo y actual método del maestro Gregorio Torres Quintero, elmente puesto en práctica por la maestra Carmen Calvillo.

Esas tardes en que saliendo de la Morelos nos íbamos a bañar en las revueltas aguas del San Pedro, donde veíamos a las mujeres lavar sobre las bateas de madera o sobre una piedra lisa. Nos sumergíamos para ver sus ácidos senos coronados por unos negros pezones 0 veíamos la negra pelambre que salía de sus axi-

\footnotetext{
Jesús López Toledo (1943-2011, México). Maestro normalista y Sociólogo, Especialista en Historia, Educación Cívica y Social, Inglés y Administración, Planeación e Investigación Educativa, Magíster y Doctor en Educación. Fue director de la Universidad Pedagógica Nacional en la ciudad de Mexicali, Baja California y profesor desde 1980 hasta su muerte. Fue también Director de Educación de Baja California, Consejero Ciudadano del primer Consejo Estatal Electoral y columnista en diversos periódicos locales y nacionales, entre otros medios de divulgación. Escribió crónica urbana, cuento y ensayo histórico, y publicó varios libros en ediciones independientes. Este texto fue publicado por primera vez en Crónicas de mística y vocación, una edición del Comité Municipal de Educación de Mexicali en 1989.
}

las cuando cargaban los enormes canastas con la ropa limpia. José Cuevas olía a tres metros de distancia, por su oído descompuesto de tanto zambullirse y bajo la supercie del agua golpear esas piedras bolas. A la mañana siguiente los ojos todavía permanecían rojos, altamente irritados, pero las horas se hacían largas esperando el momento de volver al río para pescar el chigüil, el bagre o el cauque con el pequeño anzuelo que comprábamos en la tienda mejor surtida de Tuxpan, La Tepiqueña.

Siempre que vuelvo a la casa y veo la cuarteadura de las paredes, revive en mí aquella mañana en que estando en clase un enorme estruendo nos levantó de nuestros mesabancos. Todos corrimos hacia el cancel de hierro, pero ahí la profesora Bertha Rico nos detenía diciendo que no había peligro, que nos calmáramos, mientras la profesora Obdulia García gritaba: nos están bombardeando los gringos. Luego supimos que una cohetería cercana a la escuela había hecho explosión; hubo muertos. Nadie puede olvidar ese momento porque en cada pared hay una voz que recuerda aquel gran susto.

Ya estando en sexto año, Felipe López fue acusado de robar unas tijeras, por lo que el profesor J. Trinidad Alcántar hizo su aparición en nuestro salón. Al saber que era Felipe, lo tomó de los cabellos, lo puso al frente de todos y lo golpeó inmisericordemente con manos y pies. Jamás he visto semejante acto de salvajismo por parte de un profesor, nunca he observado tanta rabia y furia desencadenada contra un alumno. 
La profesora Lorenza llegó con el nuevo año escolar y nuestro quinto grado tenía la maestra más guapa de toda la escuela. Vivía en un pequeño cuarto, a donde nos invitó en una ocasión para estudiar alguna lección que no entendimos. Cuando llegamos a su casa, nos gritó desde el baño que pasáramos, que luego saldría. Obedientemente nos sentamos por un momento porque Rodolfo Olague propuso que nos asomáramos al baño a ver a la maestra. Su propuesta tuvo aceptación inmediata y vimos entonces, por primera vez, a una mujer completamente desnuda, una hermosa mujer que habría de acompañarnos en muchos sueños agradables.

Juan Manuel Ponce, al que conocíamos por Chala porque su mamá respondía a ese nombre, fue el niño elegido para ser San Miguel, que es el patrono de las estas del pueblo. Había que tener el pelo rubio porque se supone que todos los santos son rubios, al menos así lo entendíamos. Desde el 25 de septiembre anduvo con el pelo rubio y en la escuela las bromas contra su apariencia eran cosa común. Lo vimos en el carro alegórico con su faldita dorada y su blusa blanca, con una espada golpeando a Lucifer que se hallaba a sus pies. Con los días, Juan Manuel empezó a perder el pelo como consecuencia de la pintura. A partir de entonces, una peluca sustituye al tinte y ahora muy pocos quieren ser San Miguel por un día.

Los exámenes públicos de $n$ de cursos eran un verdadero martirio para nosotros. Los padres alrededor del salón contemplaban a sus hijos contestar o quedarse callados para después llorar. No fueron pocos los compañeros que en el mismo examen fueron golpeados por sus padres al no responder al director, quien hacía las preguntas.

Hoy en la soledad, cuando mis hijos no están en casa, vuelvo a entonar los viejos cantos escolares que el maestro Cabalita, con sus cachetes a punto de reventar por las venas rojas distribuidas pródigamente sobre su blanco rostro, nos enseñaba. Me veo con mis queridos compañeros cantando: Pletórico de gente/ está de Roma el circo/ pues luchan en la arena/ atletas famosos/ Sidón, Corinto y Roma/ Atenas y Bizancio/ más el reino de Judá/ que en era lid está. Las notas del dorado saxofón salían a la calle junto con nuestros gritos. Ben Hur, el israelita y Mesala, el romano se me aparecen luchando, y yo sentado en mi mesabanco no quiero abrir los ojos, retengo fuertemente el sueño para alargarlo y sentir profundamente el viejo placer de la inocencia sepultada por el tiempo y las distancias.

La maestra Agripina Castrejón en la mañana del lunes nos platica de la tragedia ocurrida el $n$ de semana, donde Paula Salcedo mató a su hijo y lo sepultó en el excusado de madera. Luego nos pedía escribir una composición a la madre, pero nadie escribía tranquilo después de escuchar semejante historia. Aunque siempre se llevaba el primer lugar por su letra Telésforo Franco, el líder era Félix Pintado, que nadaba velozmente y destacaba en todos los deportes.

Cuando regreso a Tuxpan, los pocos amigos que quedan siempre me invitan a tomar la cerveza y el pescado zarandeado. Entre trago y bocado pasamos lista de presente, el informe nal es triste. El Guerrillas estuvo en las Islas Marías; Fernando anduvo en líos con la justicia y terminó de judicial; Olague y Vicente González son ingenieros y anduvieron por Arabia en asuntos de telefonía. Muchos murieron en riñas de cantina; otros siguen aquí compartiendo el destino con el pueblo bañados de hastío provinciano. La Escuela Morelos sigue igual, abrillantada por tantas manos de pintura como un viejo pantalón planchado miles de veces. Los maestros que todavía viven, van a diario al cine a dormir. El malecón es nido de punkillos y homosexuales. Las calles empedradas siguen recogiendo los rumores y chismes cotidianos. Lloro a escondidas por las horas que se fueron. La soledad me reconcilia con mis maestros, mis queridos maestros. Al escribir lloro de nuevo 
sintiéndome culpable de no hacerlo frente a mis profesores, para que sepan que los buenos sentimientos que intentaron meternos a fuerza y con llenados de planas sí fueron sembrados en tierra fértil. Volteo a ver mi escuela, corro en su patio de cemento, contemplo el listón de primer lugar en aseo, me asusto cuando aparece la gura del profesor J. Trinidad y me pongo la mano en la mejilla para recordar el beso amoroso que la profesora Carmen Calvillo depositó en mí cuando le presenté la lección limpia y con letra derechita.

La escuela es el nido de la dicha y la infelicidad. Es una planta recién sembrada a la que hay que regar a diario. Sitio de fantasmas que se pasean por julio y agosto recorriendo en las noches los salones, revisando que todo esté listo para el día siguiente. Siempre vuelvo a mi primaria, es decir, nunca salí de ahí. Sé que cuando reencarne lo haré en un profesor más bueno, mejor, porque así tiene que ser. Para nosotros los profesores, el mundo de los sentimientos positivos es nuestro reino, lo he comprobado cuando un ex alumno se acerca, me pregunta si soy yo, me abraza y cuando se retira lloro, porque sé que la elección fue la acertada. 
